\title{
IVAC Mutanome Vaccine
}

National Cancer Institute

\section{Source}

National Cancer Institute. IVAC Mutanome Vaccine. NCI Thesaurus. Code C113650.

An individualized, poly-neo-epitopic encoding, ribonucleic acid (RNA)-based cancer vaccine that targets a variety of patient-specific, immunogenic mutant epitopes, with potential immunostimulatory and antineoplastic activities. Upon intranodal administration, the RNA in the individualized mutanome vaccine is translated by antigen presenting cells (APCs) and the expressed protein is presented via major histocompatibility complex (MHC) molecules on the surface of the APCs. This leads to an induction of both cytotoxic Tlymphocyte (CTL) and memory $\mathrm{T}$-cell immune responses against the patient-specific neoantigens. 